\title{
THE EFFECT OF BLENDED LEARNING ON THE MOTIVATION OF ARABIAN GULF UNIVERSITY MEDICAL STUDENTS` TOWARDS LEARNING
}

\author{
Rafa Ahmed Bin Ali ${ }^{1}$, Alajab Mohammed Alajab Ismail ${ }^{2}$, Tayseer Mohammed \\ Alkhazali $^{3}$ \& Adla Bakri Hassan ${ }^{4}$ \\ ${ }^{1}$ Ministry of Education (Kingdom of Bahrain) \\ 2, $3 \& 4$ Arabian Gulf University (Kingdom of Bahrain)
}

\begin{abstract}
ABSTACT
The study investigated the effect of using a blended learning strategy based on Diagnostic Reasoning (DxR) simulation software on medical students' motivation towards learning. The study was conducted on the fourth year medical students who were studying DxR simulation software as part of Multi System Integration Unit (unit ix) at the Arabian Gulf University College of Medicine and Medical Sciences during the second semester of the academic year 2015/2016. The study sample consisted of 157 fourth year students. A quasiexperimental research time-series design with pre and posttest was used to investigate the study hypothesis. The researchers assessed the participants' motivation towards learning at two different points during the six week research experimentation. The conventional method of teaching without any e-learning or online materials was used during the first three weeks. By the end of the third week the researchers assessed the students' motivation towards learning using Instructional Materials Motivation Survey (IMMS) scale developed by John Keller (1984). Then participating students were allowed to access online materials; the electronic component of the blended learning relevant to the last three DxR cases via Blackboard LMS during the later three weeks. By the end of the sixth week, the researchers assessed again the students' motivation towards learning. Results revealed statistically significant differences between the pre and post applications in favor of the post application concerning in all dimensions of motivation. As such, it could be concluded that the blended learning was effective in enhancing university students` motivation towards learning.
\end{abstract}

Keywords: Blended learning, simulation, motivation, learning motivation and DxR software.

\section{Introduction}

In today's modern day and age, the extensive use of computer technology has become a necessity in the life of human, and it become an integral addition needed for the development of nations. The use of computers has made the life more accessible and easy, by providing several opportunities for individuals to communicate and stay in touch with people from all around the world.

The extensive uses of computer applications play a key role in the educational system. Many students interact and use educational computer programs to acquire information, to learn and practice problemsolving techniques all over the world.

These days the educational system is in a transition stage. To meet the challenges of expansion and for catering individuals need it is trying to adopt new technologies and exploring new paths to reach the goal of quality educational opportunities for all, at the same time due to various factors like deficient budgets, lack of facilities, advantages of face to face interaction, it is not completely ready to leave the traditional modes of knowledge transfer (Dangwal, 2017)

Corresponding Author: Rafa Ahmed Bin Ali / rafaaab@agu.edu.bh 
The rapid improvements at ICT (Information and Communication Technologies) influence and change the educational field. As a result of those changes, new approaches towards learning and teaching processes have come to the fore e.g., e-learning, m-learning, and b-learning (Eryilmaz, 2015).

In various sources, b-learning can also be used as blended, mixed or hybrid. B-learning combines the positive sides of elearning and conventional face to face learning methods (Finn \& Bucceri, 2004).

Dangwal (2017) defined Blended learning as an innovative concept that embraces the advantages of both traditional teaching in the classroom and ICT supported learning including both offline learning and online learning. It has scope for collaborative learning; constructive learning and computer assisted learning $(\mathrm{CAI})$.

In general, the application of computer technology in the field of education has three different modes: Computer Assisted Instruction (CAI), Computer Based Education (CBE), or Computer Managed Instruction (CMI) (Shortliffe \& Cimino, 2013).

CAI can be refered to as a self-learning technique which can be accessed both online or offline, involving interaction of students with programmed instructional materials, where computer is used to present the instructional material and monitor learning. CAI uses a combination of text, graphic sound and video to enhance the learning process. CAI programs use tutorials, drills and practice, simulation and problem solving approaches to introduce topics and test students' understanding (Adeyemi, 2012).

Blended learning incorporates face to face teaching and teaching supported by ICT; as result Blearning combines the positive features for the two approaches. Face to face learning associated with the physical presence of classrooms, textbooks, pen-and-paper examinations and teachers (Wai \& Seng, 2015). On other elearning is a kind of education system that uses communication mechanisms, computer based networks and multimedia voice, as well as accumulated information sets such as photos, graphics, libraries, necessary electronic means and software based search engines, as well as internet portals, whether remotely or in the classroom (Alshetwi, 2014).

In face to face learning instructors and students meet together in the same place and at the same time. In the face to face learning, sessions are synchronous, while no communications technologies are required for a face to face session (Caner, 2012).

Clark and Mayer (2011) defined elearning as training delivered on a digital device such as a smart phone or a laptop that is designed to support individual learning or organization goals. eLearning includes two forms; asynchronous which is designed for self-study, and synchronous form which is instructor led elearning. In this study elearning is represented by the communication though Blackboard as a Learning Management System (LMS).

By using the blended learning approach the courses could be broken up into modules that contain the learning content and activities you will have to complete. Each module usually begins with text readings, PowerPoint, and lectures that provide the information you will need to complete the assignments. The learning activities will vary each module and might include discussions, scenarios, simulations, projects, or papers (Eryilmaz, 2015).

In face to face approach the students can get personal interaction with teacher and their classmates, they get enough time to interact with their teachers and thus get influenced by their personality, behavior and value system. Face to face interaction helps in synchronous communication; teachers and students are able to get immediate feedback that in turns is favorable for teaching learning process. As a result face to face interaction is highly motivating for both the teachers and students and it gives a human touch to the process (Dangwal, 2017). 
Beside the advantages of b-learning; there are a lot of advantages of elearning in medical education such as increased accessibility to information, better updating solutions, personalized training, better distribution, standardization of content and better efficiency in achieving knowledge and skills. As result elearning has been used more frequently in the last decade to accomplish many tasks that previously took medical specialists time and effort. Moreover, a wide range of elearning modalities are integrated in medical education (Kim, 2016). eLearning motivates students to learn through the use of multimedia and interactivity, the use of multimedia and interactivity allows students to participate in their learning process, thereby improving retention. The students learn by doing and not just by listening, which encourages them to develop their knowledge and further promote learning, and this is a fundamental aspect of constructivism theory (Mufeti, 2005).

Simulation is one of the computer assisted instruction applications. Datta, Upadhyay, and Jaideep (2012) defined simulation as the artificial representation of

a complex real-world process with sufficient fidelity to achieve a particular goal, such as in training or performance testing. The aim of a simulation is to facilitate learning through immersion, reflection, feedback and practice in a similar real-life experience (Datta et al., 2012).

Medical education is one of the fields that require simulation application to help medical students to gain more practical experience with real patient cases in order to improve their related efficiency of diagnostic skills. Segerman (2013) stated that the medical education helps to ensure that the doctors acquire the necessary skills and knowledge to care for patients, however, resident duty hour restrictions have impacted the time for medical education, leaving resident educators searching for innovative options for effective medical education (Segerman, 2013). So the best way to prepare medical students for work through different patient real cases is using simulation software in an elearning environment, where more confidence will obtain. Today there is a lot of simulation software that has served medical areas, like medical exam tutor, DxR, and Care Cloud Charts. These applications offered a big opportunity for undergraduate medical students to build their clinical skills though applying into an actual situation. This study aimed to study the effect of Diagnosis Reasoning (DxR) simulation software within an elearning environment.

Medical diagnosis is a categorization task that allows physicians to make predictions about features of clinical situations and determine the appropriate course of action. Diagnosis is the core of medical practice, even during emergency situations; clinicians will not order investigations or begin treatments before they have a rough idea about what clinical problems the patient could have (Pennaforte, Moussa, Loye, Charlin, \& Audétat, 2016).

The DxR software is a powerful way to build clinical skills; real patients have been adapted to over one hundred twenty-one interactive virtual encounters, covering a broad range of clinical problems in the adult and pediatric medicine. The clinician is being used in medical and nursing schools all over the world, and it is adapted for schools of chiropractic medicine and physical therapy. Students can interview the patient, conduct physical examinations, and choose from a complete list of modern imaging, labs and diagnostic procedures. They record hypotheses, test interpretations and ultimately conduct a diagnosis and plan management.

Promoting motivation to learn is one of the main principles for efficient education (Kim and Frick, 2011). Stimulating and sustaining learner motivation is the main challenge for any educator. One approach to meet this challenge was provided by the ARCS model of motivation. ARCS model provides guidance for analyzing the motivational characteristics of a group of learners and designing motivational strategies based on this analysis. The ARCS is based on four motivational concepts: Attention, Relevance, Confidence, and Satisfaction (Keller, 2000).

Previous studies provided evidence that the elearning environment and simulation had several advantages to the students. In an elearning environment the learners play a positive role through 
engaging them in all learning processes, by providing them with the necessary feedback that encourages them toward more learning. On the other hand, simulation provides a fertile learning environment for students (Kaur, 2012).

The current study aimed to investigate the development of an elearning environment based on the DxR and evaluate its effect on the motivation of Arabian Gulf University (AGU) medical students' towards learning.

\section{Statement of the Problem}

Practicing a real situation and engaging with real-life patients are essential for mastering the diagnostic skills. Medical students were required to apply and practice continuously, to acquire and learn the needed diagnosis skills, therefore reducing medication errors and improving patient safety.

Previous studies provided evidence that learning through simulation and elearning is much better than the traditional learning methods. The fourth year medical students at AGU are de-motivated about the DxR software, which was a part of their curriculum. They resisted using the DxR software and wanted to cancel it, because they disagreed about the way of presenting DxR, also because they resisted using the technology.

The researcher confirmed the low motivation to learn and use DxR by conducting a pilot study on the fifth year students who took the DxR course previously. The pilot study was conducted in the first semester of the academic year 2015/2016 on the fifth year medical students ( $n=48)$ who took the DxR previously. The questionnaire was (Appendix L) aimed to explore the students' motivation and impression about DxR software. The findings of the pilot study revealed a low motivation means on all IMMS subscales dimensions and the total scale, which confirmed that the students were demotivated about the DxR software. The IMMS subscales means are as follows:

- Students' overall motivation $(M=2.7883, \mathrm{SD}=.91671)$.

- Students' Attention $(M=2.8142, \mathrm{SD}=.85525)$.

- Students' Relevance ( $M=2.8681, \mathrm{SD}=1.05126)$.

- Students' Confidence ( $M=2.8392, \mathrm{SD}=.79815)$.

- Students' Satisfaction ( $M=2.6413, \mathrm{SD}=.1 .30383)$.

According to the pilot study the researcher concluded some problems that influenced the students motivation towards using DxR; the students were allowed to access the DxR only at the university; they didn't have the necessary training to use DxR, they didn't have any suitable materials and multimedia related to the DxR cases, and they didn't get any feedback about their progress through the DxR cases.

\section{Hypothesis of the Study}

Based on the reviewed literature, this study investigated the following hypothesis:

1. Developing an blended learning environment based on DxR simulation software will significantly affect AGU medical students` motivation towards learning.

\section{Objectives of the Study}

This study attempted to achieve the following objectives:

1. Set a list of standards for developing an blended learning environment based on DxR simulations software.

2. Develop a blended learning environment based on DxR simulation software for enhancing AGU medical students' diagnostic skills and motivation towards learning. 
3. Investigate the effect of developing blended learning environment based on DxR on the medical students`diagnostic skills.

4. Investigate the effect of developing blended learning environment based on DxR simulation on the medical students' motivation towards learning.

5. Suggest some recommendations for future of blended learning and computer simulation in the medical field.

\section{Significance of the Study}

The significance of this study lies in its attempt to:

- $\quad$ Find solution for lack of motivation among students regarding using DxR.

- Help medical students to practice DxR in their own time in more attractive way.

- Develop blended learning environment in systematic way that attracts students and motivates their learning

- Provide evidence on the effectiveness of blended learning and DxR software on medical students learning outcomes and motivation.

- Inform concerned people about the importance of learning management systems on students' diagnostic skills and motivation.

- Reveal the importance of simulation system and its effects on students' diagnostic skills and motivation.

\section{Study Questions}

The primary question of the study is: "What are the effects of developing a blended learning environment based on DxR simulation software on the motivation of AGU medical students' towards learning experience in the medical field?" Four sub questions were driven from the above main question:

1. What are the standards for developing the proposed blended learning environment based on DxR Software to enhance students' diagnostic skills and motivation towards learning?

2. What is the instructional design of the proposed blended learning environment based on DxR Software like?

3. What is the effect of developing a blended learning environment based on DxR simulation software on AGU medical students` diagnostic skills?

4. What is the effect of developing a blended learning environment based on DxR simulation software on AGU medical students` motivation towards learning?

\section{The Study Limitations}

The results of the present study can only be generalized within the following limitations:

1) The human limitations: Fourth year medical students.

2) The institution limitations: Arabian Gulf University College of Medicine and Medical Sciences.

3) The time limitations: Second semester of the academic year 2015/2016.

4) The content limitations: Clinical diagnostic skills included in DxR simulation software.

\section{Research Methodology and Procedures \\ Research Design}

In order to achieve the aim of the presented study, a mixed method approach involving both quantitative and qualitative approaches were employed. A pilot study was conducted by the researcher in the first semester of the academic year 2015/2016 to confirm and understand the reasons for the lack 
of motivation among students and to provide insights that helped the researcher to find solution regards the problem of the research.

The researcher adopted the quasi-experimental research method to test the effects of the primary independent variable (blended learning) and the secondary independent variable (DxR simulation software) on students' motivation as the study dependent variable. The researcher used experimental research with time-series design method. This design method adopted on the assessments of the same variables at different points in time, the sample consisted of all fourth year medical students at AGU. The research used one group pre-test, post-test method to assess the students' diagnostic skills and motivation toward learning.

\section{Population and Sample of the Study}

The sample of the study was the same as the population which consisted of all fourth year medical students enrolled in unit IX at AGU in the second semester of the academic year 2015/2016 (Unit IX is the last unit in phase II, before students start phase III, which is the clinical phase). The members of the study were 157 students; 70 males and 87 females, they served as both the experimental and the control group. Their ages between 20 and 23 years and the mean of their ages was 22 (S.D. $=0.87051$ ). Concerning their previous unit score, their scores ranged between 53 and 95.27, with an average of 76.5721, and $\mathrm{SD}=8.01603$ (see Table 1).

Table 1

Characteristics of the Sample of the Study

\begin{tabular}{|c|c|c|c|}
\hline & Variable & Frequency & $\%$ \\
\hline \multicolumn{4}{|c|}{ Previous unit score } \\
\hline & Mean & & 76.5721 \\
\hline & Maximum & & 95.27 \\
\hline & Minimum & & 53.00 \\
\hline \multirow[t]{5}{*}{ Std. Deviation } & & & 8.01603 \\
\hline & Age & & \\
\hline & Mean & & 21.8229 \\
\hline & Maximum & & 23.00 \\
\hline & Minimum & & 20.00 \\
\hline \multirow[t]{7}{*}{ Std. Deviation } & & & .87051 \\
\hline & Gender (IMMS scale participants) & & \\
\hline & Males & 59 & 40.7 \\
\hline & Females & 86 & 59.3 \\
\hline & Gender (DxR Diagnostic Skills) & & \\
\hline & Males & 69 & 44.2 \\
\hline & Females & 87 & 55.8 \\
\hline
\end{tabular}

\section{Research Instruments}

In order to achieve the study aims, the researcher depended on the following instrument:

\section{Instructional Materials Motivation Scale (IMMS)}

To assess the effect of the proposed blended learning strategy on AGU medical students' motivation towards learning, and after obtained permission from the author (Prof. John Keller) to use and modify the IMMS questionnaire (see Appendix D), the researcher adapted IMMS scale. Students asked to think about each statement in relation to the unit itself, and to indicate how true each statement is. The response scale ranges from 1 (Not true of me) to 5 (Very true of me). Therefore, the minimum score on the 36 item survey is 36 , and the maximum is 180 with a midpoint of 108 . The minimums, maximums, 
and midpoints for each subscale vary because they do not all have the same number of items. There were 5 subscales: one for each of the ARCS components and one for the ARCS total score.

Keller's ARCS Model of motivational design describes students' motivation to learn in terms of four characteristics: Attention (for arousing and sustaining curiosity and interest), Relevance (strategies that link learners' needs, interests and motives), and Confidence (strategies that help students develop a positive expectation for successful achievement), and Satisfaction (strategies that provide extrinsic and intrinsic reinforcement for effort).

The ARCS model is the most widely-used motivational model applied to the design and development of computer-assisted instruction programs and elearning environments ( $\mathrm{Hu}, 2008$ ); According to Gabrielle ARCS model reduces attrition rate in distance learning programs and improve learners' selfdirected learning (cited in: Hu, 2008 ). Development process of ARCS consisted of two phases:

- Item development: After reviewing the concepts and strategies that comprise the ARCS model and a variety of instruments used to measure motivational constructs, a pool of items was prepared. These were reviewed by 10 graduate students who were well versed in the motivational literature. They responded to each item then discussed the items which seemed ambiguous, unrelated to the appropriate higher-order concept (i.e., attention, relevance, confidence, or satisfaction), or otherwise difficult to respond to.

- Ambiguity check: The original item pool was reduced, revised, and administered to ten adults who were told to respond to it twice. The first time they were to "fake good," and the second time to "fake bad." That is, they were to assume they were taking a course which was highly motivating, and to answer each item in a way that would indicate their highly positive motivation. Secondly, they were to assume that the course was totally unmotivated, and to answer accordingly. This test revealed a few items that could "go either way," i.e. potentially poor discriminators. These items were then revised or deleted and retested.

IMMS scoring. John Keller developed the IMMS scale to measure students' motivational reactions to self-directed instructional materials. IMMS separates the 36 questions into the four related ARCS elements as a means of measuring learner motivation associated with that element. The Relevance and confidence subscales both have 9 items, the Satisfaction subscale has 6, and the Attention subscales has 2 (Keller, 2009). Students responses recorded (from 1 to 5) as follow: 1 (or A) $=$ Not true, $2($ or $\mathrm{B})=$ slightly true, $3($ or $\mathrm{C})=$ moderately true, $4($ or $\mathrm{D})=$ Mostly true and $5($ or $\mathrm{E})=$ Very true.

Each of the four dimensions of ARCS model has number of items, the survey scored for each of the four subscales or the total scale score (see Table 2). The response scale ranges from 1 to 5 ; this means that the minimum score on the 36 item survey is 36 , and the maximum is 180 with a midpoint of 108 . The minimums, maximums, and midpoints for each subscale vary because each of the four dimensions do not all has the same number of items.

Table 2

IMMS Scoring Guide

\begin{tabular}{rrrr}
\hline Attention & Relevance & Confidence & Satisfaction \\
\hline 2 & 6 & 1 & 5 \\
8 & 9 & 3 (Reverse) & 14 \\
11 & 10 & 4 & 21 \\
12 (Reverse) & 16 & 7 (Reverse) & 27 \\
15 (Reverse) & 18 & 13 & 32 \\
17 & 23 & 19 (Reverse) & 36 \\
20 & 26 (Reverse) & 25 & \\
22 (Reverse) & 30 & 34 (Reverse) & 35 \\
24 & 33 & & \\
\hline
\end{tabular}


28

29 (Reverse)

31 (Reverse)

Scores were determined by summing the responses for each subscale and the total scale. Ten of the 36 questions were negatively worded to increase the strength of the questionnaire, they were marked reverse (see Table 2); the responses have to be reversed before they can be added into the response total. That is, for these items, $5=1,4=2,3=3,2=4$, and $1=5$.

IMMS reliability. The researcher tested the reliability of ARCS motivation survey; by conducting a pilot study on the fifth year medical students at AGU who took DxR previously as a part of unit IX.

The reliability of Instructional Materials Motivation Survey (IMMS) as internal consistency was confirmed by using Cronbach correlations Alpha by finding reliability coefficients for each of the four dimensions and the total score in all dimensions for the pilot sample on post-test. The survey was administered to a total of 48 students. The reliability coefficients obtained and compared with Keller's and Maheen Ghawas (2009) IMMS reliability coefficients. The reliability coefficients results for the composite sub-dimensions of the IMMS and the total score ranged from 0.858 to 0.968 ; suggested scale has good reliability which suggested that ARCS survey is valid for implementation on the major study sample (see Table 3).

Table 3

IMMS Reliability and Computed Cronbach's Alpha for IMMS Test

\begin{tabular}{|c|c|c|c|c|c|}
\hline Scale Reliability & Attention & Relevance & Confidence & Satisfaction & Total Scale \\
\hline Estimated (Cronbach $\boldsymbol{\alpha})$ & .89 & .81 & .90 & .92 & .96 \\
\hline $\begin{array}{l}\text { Computed (Cronbach } \alpha) \\
\text { by the researcher }\end{array}$ & 858 & 923 & .780 & 0.968 & 0.964 \\
\hline $\begin{array}{l}\text { Computed (Cronbach } \boldsymbol{\alpha}) \\
\text { By Maheen Ghawas }\end{array}$ & 0.962 & 0.898 & 0.916 & 0.939 & 0.981 \\
\hline
\end{tabular}

The researcher presented the IMMS scale to the supervisors and they agreed upon the modification made by the researcher on the IMMS, and their suggestions concentrated on:

- Replacing word "topic" with the word "unit".

- $\quad$ Rewording some statements to make them easier and clearer for students. The researcher made the necessary modifications on IMMS scale (Appendix G), and reviewed by the supervisors again, and then the researcher finalized it to contain three major sections and published it through Google doc (Appendix L):

- The introductory section included students' demographic data: Name, ID number, previous unit score, gender, and nationality.

- The second section contained 36 questions used a to measure learner motivation.

- Last section allowed the students to write any comments and suggestions.

The researcher revised more studies concerning elearning to make sure that the dimensions adopted earlier were suitable and fit the study purposes. These studies were also used to find out the most suitable statements for the scale dimensions. These studies are:

- The study conducted by Margueratt (2007) which investigated the students' motivation with enhanced instructional design.

- The study conducted by Serio, Ibáñez and Kloos (2013) that investigated the effect of reality system on students' motivation for a visual art course.

- A comparative study conducted by Chaiprasurt \& Esichaikul (2013) which provided communication tools on mobile phone that impact motivation. 
- A study conducted by Rigby (2015), which examined the use of simulation as an instructional strategy in a highly theoretical aeronautical science aerodynamics course.

- A study conducted by Huang \& Hew (2016) that measured learners' motivation level in Massive Open Online Courses.

- A study conducted by Gonen and Akbarov (2016) measured the effect of blended learning on language learners' motivation with ARCS model.

IMMS internal validity. The internal validity of sub-dimensions was confirmed; these sub-dimensions constitute the IMMS through determining Pearson's correlation coefficients between the subdimensions for the pilot sample responses to the post-test and the total score of the dimensions. Correlation coefficients between sub-dimensions of the IMMS and the total score indicated statistically significant differences at the level 0.01 which showed that the scale has a high significant validity (see Table 4).

Table 4

Pearson's Correlations Coefficients of the IMMS Sub-dimensions

\begin{tabular}{lllllll}
\hline & & & Attention & Relevance & Confidence & Satisfactio \\
& & Total Scale & Subscale & Subscale & Subscale & n Subscale \\
\hline Total & Pearson Correlation & 1 & $.940^{* *}$ & $.943^{* *}$ & $.910^{* *}$ & $.932^{* *}$ \\
Scale & Sig. (2-tailed) & & .000 & .000 & .000 & .000 \\
& $\mathrm{~N}$ & 45 & 45 & 45 & 45 & 45 \\
Attention & Pearson Correlation & $.940^{* *}$ & 1 & $.815^{* *}$ & $.842^{* *}$ & $.807^{* *}$ \\
Subscale & Sig. (2-tailed) & .000 & & .000 & .000 & .000 \\
& $\mathrm{~N}$ & 45 & 48 & 48 & 47 & 46 \\
Relevance & Pearson Correlation & $.943^{* *}$ & $.815^{* *}$ & 1 & $.799^{* *}$ & $.888^{* *}$ \\
Subscale & Sig. (2-tailed) & .000 & .000 & & .000 & .000 \\
& $\mathrm{~N}$ & 45 & 48 & 48 & 47 & 46 \\
Confidenc & Pearson Correlation & $.910^{* *}$ & $.842^{* *}$ & $.799^{* *}$ & 1 & $.776^{* *}$ \\
e Subscale & Sig. (2-tailed) & .000 & .000 & .000 & & .000 \\
& $\mathrm{~N}$ & 45 & 47 & 47 & 47 & 45 \\
Satisfactio & Pearson Correlation & $.932^{* *}$ & $.807^{* *}$ & $.888^{* *}$ & $.776^{* *}$ & 1 \\
n Subscale & Sig. (2-tailed) & .000 & .000 & .000 & .000 & 46 \\
& $\mathrm{~N}$ & 45 & 46 & 46 & 45 & \\
\hline
\end{tabular}

**. Correlation is significant at the 0.01 level (2-tailed).

\section{The Procedures}

The following procedures carried out by the researcher:

1. The researcher reviewed the related literature for better understanding the problem, justified the reasons for the current study, and concentrated on the studies that demonstrated on Keller's ARCS Model of motivational design, and simulation as computer assisted learning.

2. It should be mentioned that before contacting AGU administration formally, a pilot study was conducted in the first semester of the academic year 2015/2016 on the fifth year medical students (see chapter one) and based on the information from the students' responses, the researcher addressed the AGU administration formally and presented the need to employ an elearning management system which was the blackboard to present the DxR simulation 
software in more interactive and attractive way using multimedia and LMS components to encourage the students to use and get benefit from the DxR.

3. On the first semester of 2015/2016 academic year, the researcher obtained the permission from the AGU dean, and the research and ethics committee to apply the study during the second semester of the academic year 2015/2016 on fourth year students who will take DxR as a part of unit IX (Appendix A, B and C). The researcher reviewed the syllabus and DxR problems were chosen. The researcher began to design the elearning environment by following the ADDIE instructional.

4. The researcher then developed the proposed b-learning environment and uploaded the enrichment online materials. The proposed b-learning environment was evaluated by research supervisors after that the researcher made all the necessary modifications (Appendix I).

5. The researcher adapted an instrument proposed and constructed by John Keller's (2006) for measuring students' motivation IMMS. It was then judged and evaluated by academic Professors from the Distance Teaching and Training Program and Aljawhara Center of Genetics in the beginning of March 2015 (Appendix G).

6. The students were added to the blackboard module and given the account details to log on.

7. The researcher then met the supervisors in February to determine the exact date of application.

8. The researcher started the experiment on the 6th of March 2016, the students took the first three DxR cases (one case per week: Case 1 on the 6th of March, case 2 on the 13th of March, case 3 on the 20th of March) in a traditional face to face approach, students practiced the cases without any online materials and without feedback about their DxR progress from the researcher or instructor. By the end of the third week, the measured the students' motivation towards learning using online IMMS scale.

9. After that the researcher started the study intervention which took another three weeks from the 27th of March and ended on the 10th of April (one case per week: Case 4 on the 27th of March, case 5 on the 3rd of April, case 6 on the 10th of April) and applied it as follows:

- All students were given a Blackboard username and password.

- A Blackboard Manuel guide (Appendix M and N) was prepared and sent to all students by e-mail. The manual guide provided the students detailed instructions on how to use and login into blackboard, how to navigate through Blackboard components, how to download the needed DxR online materials (e.g., video, audio, text, web links, online quizzes) related to the DxR cases.

- The students started working and accessing the online materials and DxR trials and by the end of the sixth week, the researcher measured the students' motivation towards learning again.

- The researcher conducted a weekly discussion with students to discuss any problems or issues related using elearning environment.

\section{Results of the Study}

\section{Results Related to the Equivalence between Males and Females}

The researcher tested the equivalence between males and females as a control variable to ensure that the gender was not a threat variable with respect to motivation. The results were analyzed using an independent-sample t-test. For total scale, $\mathrm{t}(143)=0.796 ; \mathrm{p}=0.427$. For Attention subscale, $\mathrm{t}(143)=$ 0.584; $\mathrm{p}=0.560$, For Relevance subscale t $(143)=0.566 ; \mathrm{p}=0.572$, For Confidence subscale $\mathrm{t}(143)=$ $0.790 ; p=0.431$, For Satisfaction subscale $t(143)=1.098 ; p=0.274$. The sample means were 
displayed in Figure 1, which shows that males group demonstrated scores on DxR which were quite similar to those shown by females group in all motivation subscales plus the total scale. Arithmetic means and standard deviations for males and females in motivation scale were shown in Table 5 which revealed that there were no statistically significant differences between the means scores of the males and females scores $(\alpha \leq 0.025)$. Result totally demonstrated the equivalence between males and females in motivation scale.

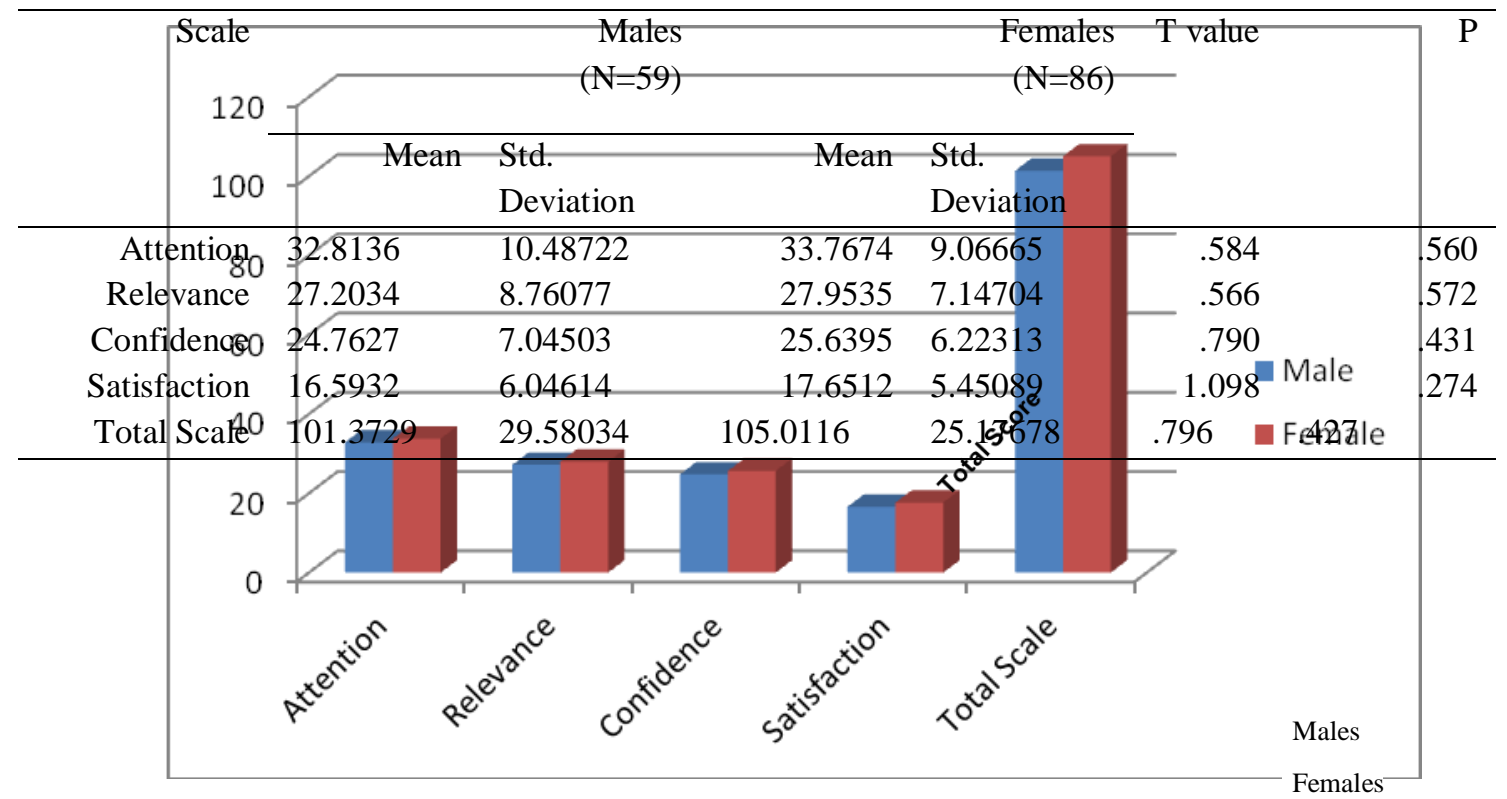

Figure1. Comparison between males and females mean scores in the IMMS dimension before experiment

Table 5

Independent Sample t-test Results for the Significance of Differences between the Males and Females Responses to the IMMS Dimensions on the Pre test

\section{Results Related to the Second Hypothesis}

Motivation represents the basic of self-learning. The students used all elearning tools and strategies towards reaching the goals of DxR software efficiently and they became characterized by selfconfidence, achievement and high level of ambition, curiosity and attention, therefore the students satisfied with the DxR elearning environment; because it was highly relevant to the unit they studied.

The second hypothesis stated that: "Developing an elearning environment based on DxR simulation software will significantly affect AGU medical students`motivation towards learning". To verify the effectiveness of the proposed elearning environment based on DxR simulation software for increasing the students' motivation. The researcher used paired sample T-test to determine the statistical differences between the post and pre application on 145 students (valid responses). Arithmetic means and standard deviations for pre and post responses to the IMMS scale were extracted as shown in Table 
6, which shows that there were statistically significant differences between the mean scores of the students' responses to all motivation dimensions plus the total score in the pre and post test in favor of the post test; all the $\mathrm{p}$ values for these dimensions were statistically significant at the level of $\alpha \leq 0.05$. Results totally demonstrated the effectiveness of the program for increasing the students' motivation, which taught by using the elearning environment and the results indicated to the acceptance of the second hypothesis of the research hypotheses.

Table 6

Paired-Sample T test Results for the Significance of Differences between for the Students' Responses to the Test Dimensions on the Pre-Post Test

\begin{tabular}{|c|c|c|c|c|c|c|c|}
\hline \multirow{2}{*}{ Scale } & \multirow{2}{*}{$\begin{array}{r}\text { Maximum } \\
\text { value }\end{array}$} & \multicolumn{2}{|c|}{$\begin{array}{r}\text { Pre motivation } \\
\text { Scale }\end{array}$} & \multicolumn{2}{|c|}{ Post motivation Scale } & \multirow[t]{2}{*}{$\begin{array}{r}\mathrm{T} \\
\text { value }\end{array}$} & \multirow[t]{2}{*}{$\mathrm{P}$} \\
\hline & & Mean & $\begin{array}{l}\text { Std. } \\
\text { Deviation }\end{array}$ & Mean & Std. Deviation & & \\
\hline Attention & 60.00 & 33.3793 & 9.64586 & 39.2897 & 10.97973 & 6.324 & .000 \\
\hline Relevance & 45.00 & 27.6483 & 7.82316 & 31.4759 & 8.31505 & 5.388 & .000 \\
\hline Confidence & 45.00 & 25.2828 & 6.56030 & 30.9793 & 7.70053 & 8.530 & .000 \\
\hline Satisfaction & 30.00 & 17.2207 & 5.70388 & 20.4345 & 6.39967 & 5.666 & .000 \\
\hline Total Scale & 180 & 103.5310 & 27.01493 & 122.1793 & 30.99679 & 7.275 & .000 \\
\hline
\end{tabular}

This analysis revealed significant differences between mean levels of all motivation scale dimensions plus the total scale observed in the post application. The sample means were displayed in Figure 2, which shows that means after intervention were significantly higher in all scale dimensions plus total scale than in the pre application.

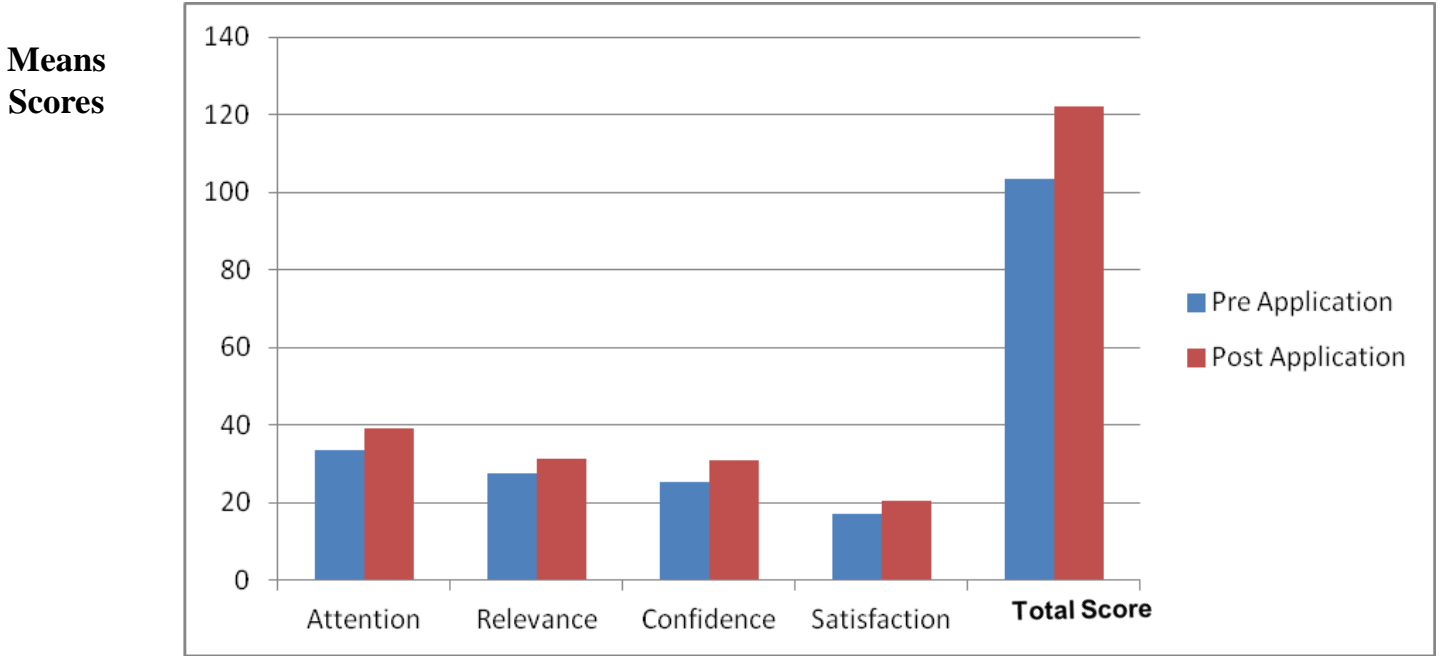

Figure 2. Means of IMMS dimensions before and after the experiment 
For total scale, $\mathrm{t}(144)=7.275 ; \mathrm{p}=0.00$. The sample means are displayed in Figure 3, which shows that the mean of the total scale scores were significantly higher in post application $(\mathrm{M}=122.1793, \mathrm{SD}=$ 30.99679) than in the pre application $(\mathrm{M}=103.5310, \mathrm{SD}=27.01493)$.

Means

Scores

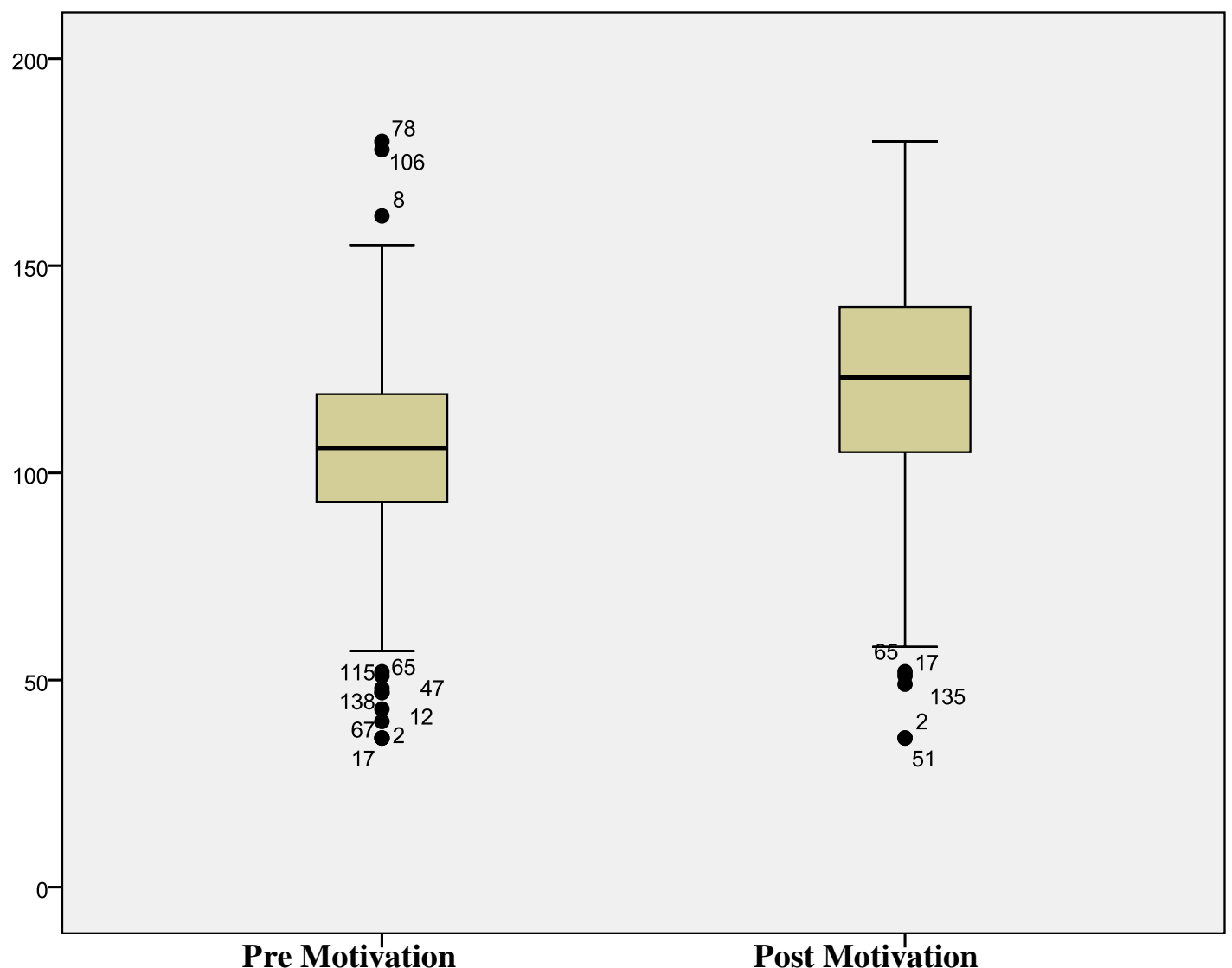

Figure 3. The total score means before and after experiment

For Attention subscale, $\mathrm{t}(144)=6.324 ; \mathrm{p}=0.00$. The sample means are displayed in Figure 4, which shows that mean of Attention subscale scores were significantly higher in post application $(\mathrm{M}=$ 39.2897, $\mathrm{SD}=10.97973)$ than in the pre application $(\mathrm{M}=33.3793, \mathrm{SD}=9.64586)$. 


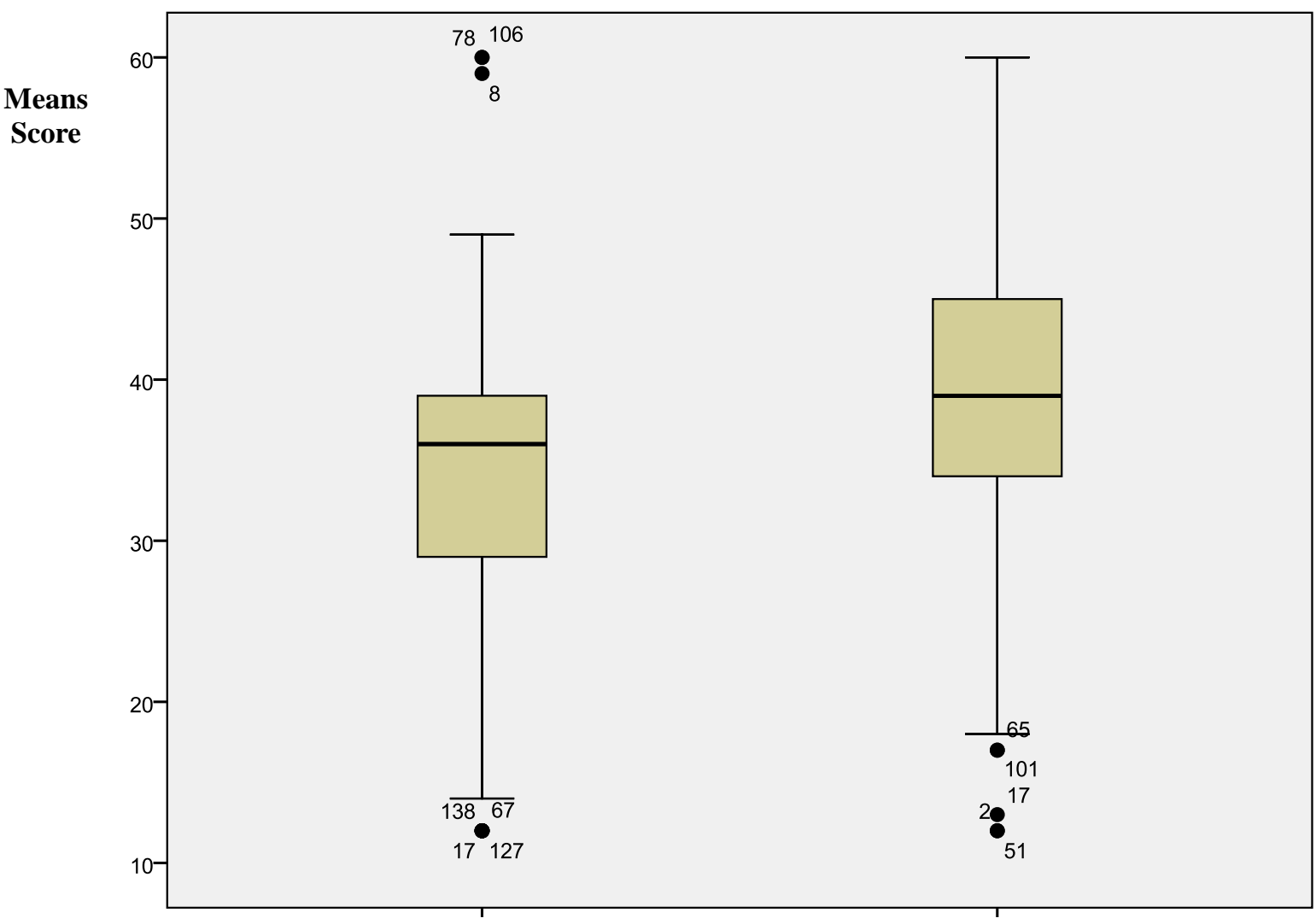

Figure 4. Means of attention subscale before and after experiment

For Relevance subscale $\mathrm{t}(144)=5.388 ; \mathrm{p}=0.00$, The sample means are displayed in Figure 5, which shows that mean of Attention subscale scores were significantly higher in post application $(\mathrm{M}=$ $31.4759, \mathrm{SD}=8.31505$, $)$ than in the pre application $(\mathrm{M}=27.6483, \mathrm{SD}=7.82316)$. 


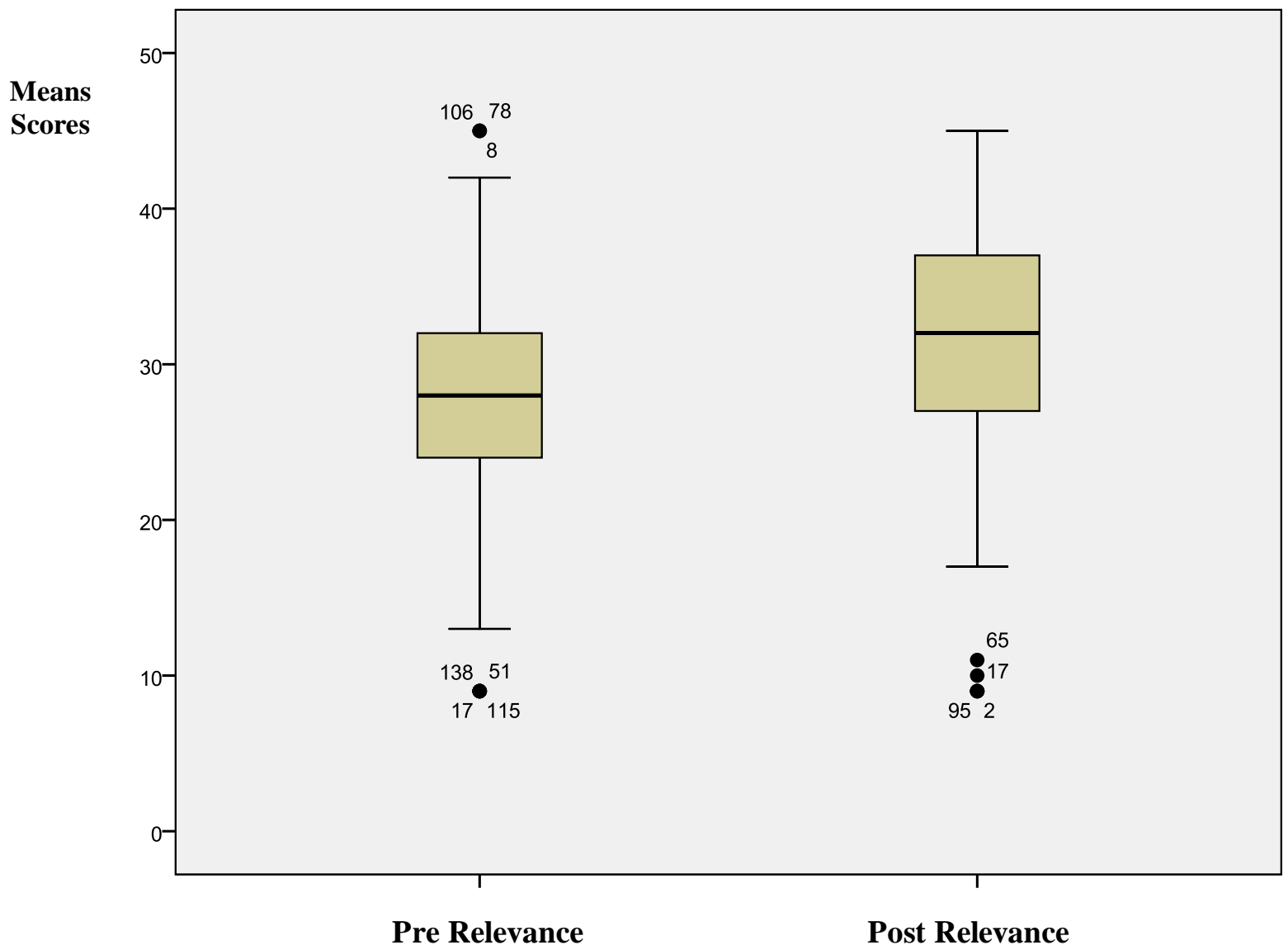

Figure 5. Means of relevance subscale before and after experiment

For Confidence subscale , $\mathrm{t}(144)=8.530 ; \mathrm{p}=0.00$, The sample means are displayed in Figure 6, which shows that mean of Confidence subscale scores were significantly higher in post application $(\mathrm{M}=$ $30.9793, \mathrm{SD}=7.70053)$ than in the pre application $(\mathrm{M}=25.2828,, \mathrm{SD}=6.56030)$. 


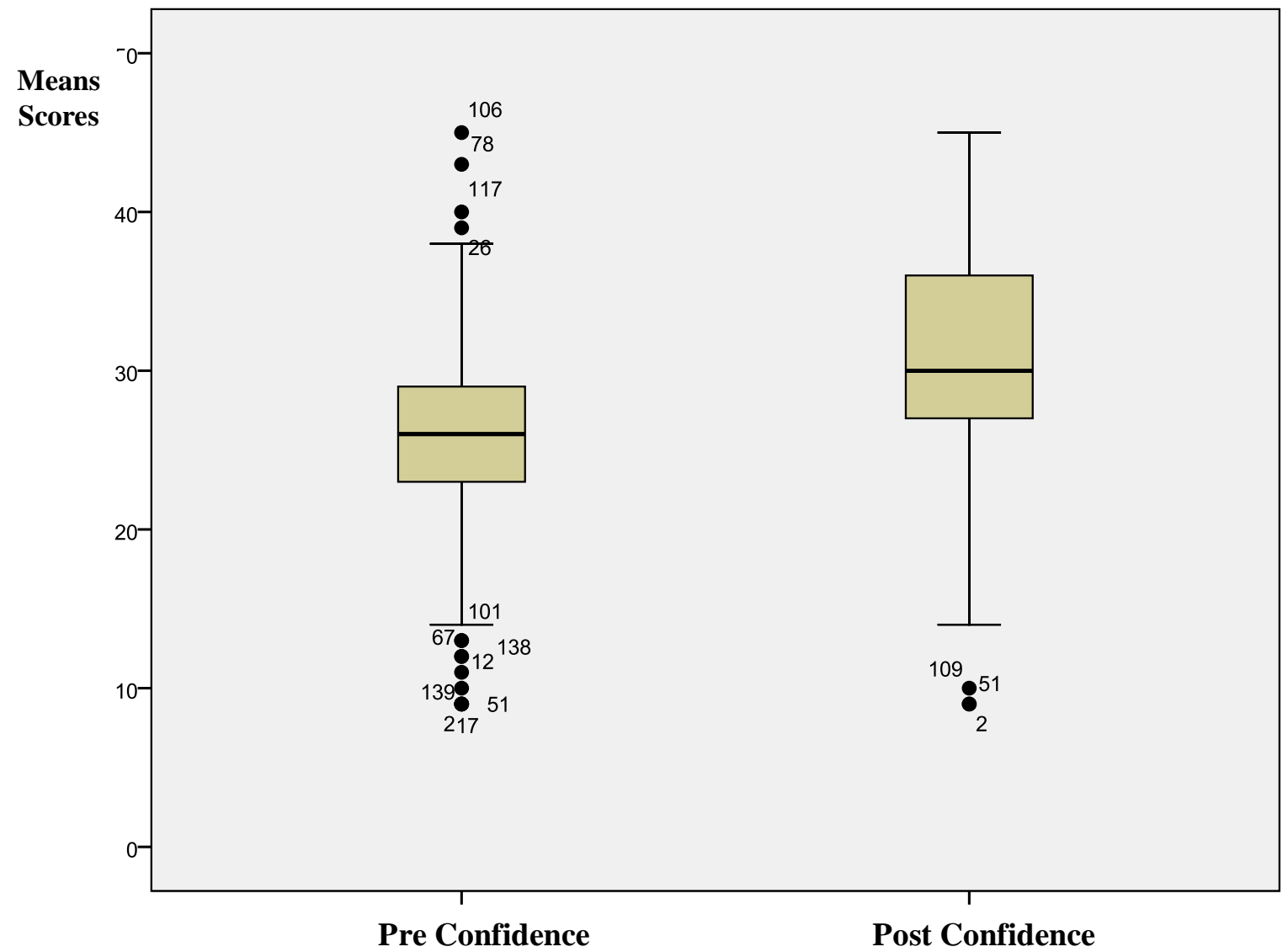

Figure 6. means of confidence subscale before and after experiment

For Satisfaction subscale $\mathrm{t}(144)=5.666$, The sample means are displayed in Figure 7, which shows that mean of Satisfaction subscale scores were significantly higher in post application $(\mathrm{M}=20.4345,, \mathrm{SD}=$ $6.39967)$ than in the pre application $(\mathrm{M}=17.2207, \mathrm{SD}=5.70388)$. 


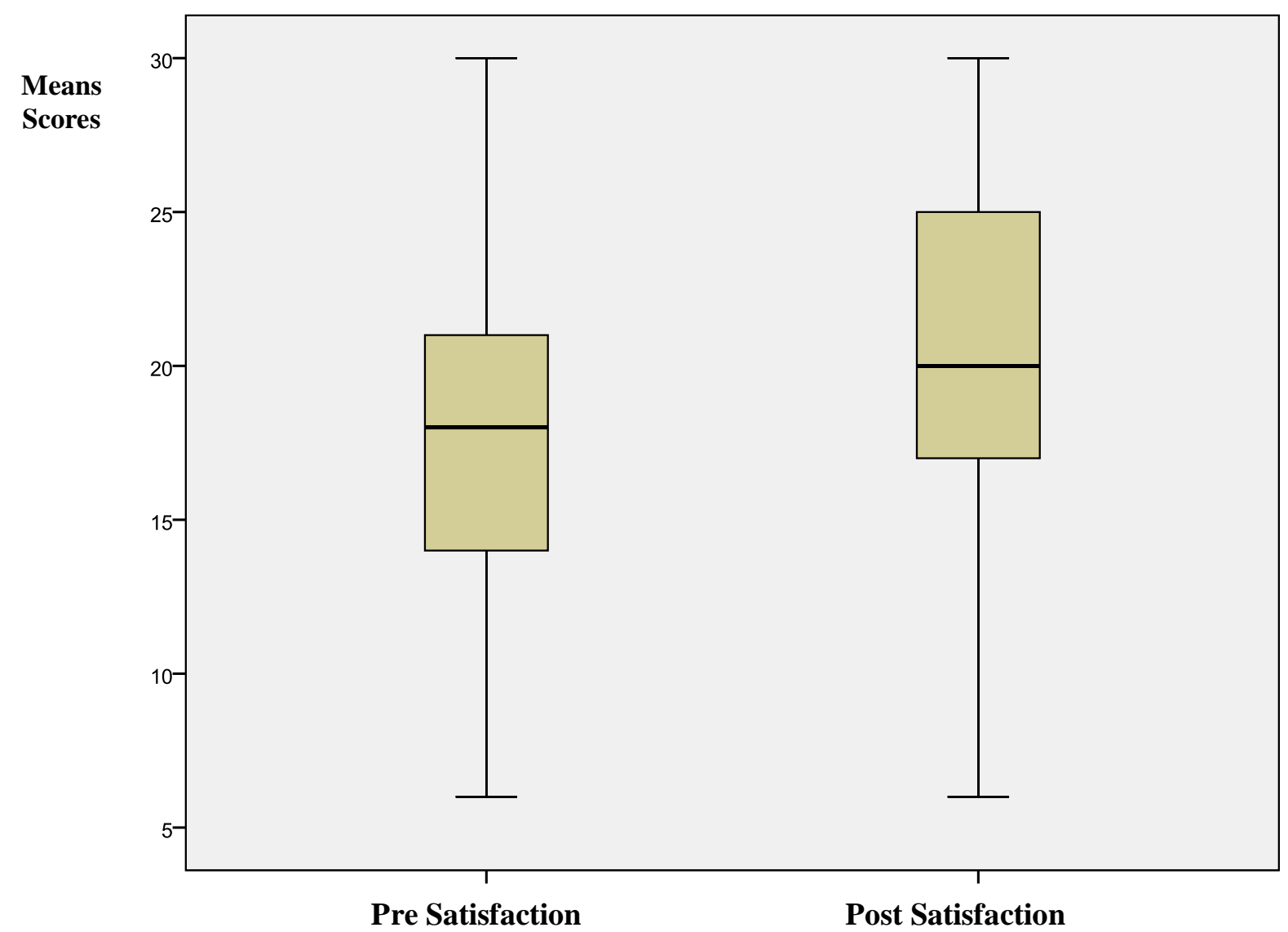

Figure 7. Means of satisfaction subscale before and after experiment

\section{The Effect Size of the eLearning Environment on Students' Motivation}

As shown in Table 7, the effect size of the elearning environment is 0.269 which considered as a large effect $\left(\eta^{2}>0.14\right)$.

Table 7

Effect Size of eLearning on the Learners' Motivation

\begin{tabular}{lllll}
\hline $\mathrm{N}$ & t-value & df & $\boldsymbol{\eta}^{2}$ & Effect Size \\
\hline 145 & 7.275 & 144 & 0.269 & Large \\
\hline
\end{tabular}

To examine the efficiency of elearning environment, the researcher calculated Cohen's effect size value $(\mathbf{d}=2.56$ ); which suggested a high practical significance (Cohen's $d>0.8$ ) based on benchmarks suggested by Cohen (1988), which means that elearning helped the students, on average, to improve their scores with about 2 standard deviation (see Table 8).

Table 8

Practical Significance of eLearning on Students' Motivation

\begin{tabular}{lrll}
\hline t-value & Mean Difference & Cohen's $d$ & Effect Size \\
\hline 7.275 & 18.6483 & 2.56 & Large \\
\hline
\end{tabular}




\section{Discussion}

\section{Discussion of the Results Related to the study Hypothesis}

The researcher believed that the improvement in motivation was due to:

- The proposed elearning helped to gain students' attention, inform learners about objectives, stimulate and recall prior learning, present content, provide learning guidance and feedback, elicit performance, assess performance, and enhance retention and finally transfer the learning to other DxR cases; these Gagne's events provide a framework for an effective learning process which led to motivate students to learn and practice DxR cases.

- The interaction between students and the design of the DxR environment which was clear through the students' emails, impressions and comments in the post questionnaire.

- Students' engagement with all the learning materials provided by elearning environment i.e., video, text, web links, the participation through the discussion board and the varied presentation formats that enhanced the overall students' motivation.

- The use of various elearning format such as audio, video, text and hypertext was effective in teaching DxR course as compared to the traditional way for using DxR.

- The communication between the researcher and students had a great impact on increasing the students' motivation; the immediate and frequent feedback also played a key role in the development of learners' confidence.

- Simple and easily navigation system within the elearning improved the student' satisfaction with the way the DxR was presented in.

Results driven by many studies agreed with the current study, including Rovai, Ponton, Wighting and Baker's (2007) comparative study whose subjects were undergraduate students. The research results provided evidence that the students in an elearning environment possess stronger motivation than on campus students who attend $\mathrm{f} 2 \mathrm{f}$ classes.

Also, as one can see in the Margueratt (2007) study on students who took a distance learning Defense Management course from the Royal Military College, the results showed that there was a discernible improvement in learner motivation associated with each ARCS element between lessons that had been altered using instructional techniques designed to improve learner motivation and those that had not been altered.

Finally, a study conducted by Kleinert al. (2015) aimed to develop an educational content module that teaches clinical and therapeutic workflows in surgical oncology, which examines how the use of this module affects student performance. The new module was based on Immersive Patient Simulators (IPS) named ALICE (Artificial Learning Interface for Clinical Education). ALICE was evaluated on 62 third-year students. Students showed a high degree of motivation when using the simulator as most of them had fun using it. It also showed a positive impact on the clinical reasoning as there was a significant improvement in determining the correct therapy after using the simulator.

\section{Recommendations}

Based on the findings of the study the researcher recommended the following:

- Constructive learning should be encouraged, in which the opportunity should be given to learners to construct their own meaning from the information and materials presented in the elearning environment and DxR different cases.

- The use of interactive learning objects related to DxR cases to meet the needs of individual learners.

- AGU should encourage medical educators to practice and adopt b-learning approach.

- $\quad$ Training on elearning and DxR should be made for all students and staff at AGU.

- Designing instructional e-courses for medical students with aid from elearning experts to save medical educators' effort and time. 
- Encouragement of the implementation of DxR simulation software that serves the medical field at AGU.

- Videotaping the core topics in the pre-clinical phase.

- Applying DxR course from the second year at AGU.

\section{Suggestions for Future Studies}

Based on the research results, the researcher recommended conducting further studies as follow:

- Studies should be conducted to determine the effect of b-learning on other medical courses.

- Conducting further studies to explore more benefits of using b-learning and simulation.

- Promote and conduct interactive multi-disciplinary research to broaden ICT integration in the medical field.

- Study the effectiveness of using the latest technology products.

\section{References}

Adeyemi, B. A. (2012). Effects of computer assisted instruction (CAI) on students achievement in social studies in Osun state, Nigeria. Mediteranean Journal of Social Sciences, 3(2), 269-277.

Alshetwi, A. S. (2014). Quality of High-Tech eLearning in Saudi Universities. International Journal of u-and e-Service, Science and Technology, 7(6), 319-326.

Caner, M. (2012). The definition of blended learning in higher education. In P. Anastasiades (Ed.), Blended Learning Environments for Adults: Evaluations and Frameworks. Hershey, PA: IGI Global. doi:10.4018/978-1-4666-0939-6.ch002

Chaiprasurt, C., \& Esichaikul, V. (2013). Enhancing motivation in online courses with mobile communication tool support: A comparative study. The International Review of Research in Open and Distributed Learning, 14(3), 377-401.

Clark, R. C., \& Mayer, R. E. (2011). eLearning and the science of instruction: Proven guidelines for consumers and designers of multimedia learning. San Francisco: CA: Pfeiffer.

Dangwal, K. L. (2017). Blended Learning: An Innovative Approach. Universal Journal of Educational Research, 5(1), 129-136.

Datta, R., Upadhyay, K. K., \& Jaideep, C. N. (2012). Simulation and its role in medical education. Medical Journal Armed Forces India, 68(2), 167-172.

Di Serio, Á., Ibáñez, M. B., \& Kloos, C. D. (2013). Impact of an augmented reality system on students' motivation for a visual art course. Computers \& Education, 68(1), 586-596.

Eryilmaz, M. (2015). The effectiveness of blended learning environments. Contemporary Issues in Education Research (Online), 8(4), 251.

Gonen, K.., \& Akbarov, A. (2016). Measuring the effect of blended learning on language learners' motivation with ARCS model. International Journal of ELT, Linguistics and Comparative Literature, 4(1). Retrieved from http://journalofelt.kypublications.com/4.1.16/KEMAL\%20GONEN\%201-9.pdf.

Finn, A. and Bucceri, M. (2004). A case study approach to blended learning, retrieved January 15, 2008 from http://www.centra.com/download/whitepapers/CaseStudy_BlendedLearning.pdf

Huang, B., \& Hew, K. F. (2016). Measuring Learners' Motivation Level in Massive Open Online Courses. International Journal of Information and Education Technology, 6(10), 627-636. 
Kaur, H. (2012). Do we really need computers in classroom instructions?. International Journal of Computers \& Technology, 2(3a), 64-66.

Keller, J. M. (2000). How to integrate learner motivation planning into lesson planning: The ARCS model approach. VII Semanario, Santiago, Cuba, 1-13. Retrieved from http://apps.fischlerschool.nova.edu/toolbox/instructionalproducts/itde8005/weeklys/2000-KellerARCSLessonPlanning.pdf

Kim, K. J., \& Frick, T. W. (2011). Changes in student motivation during online learning. Journal of Educational Computing Research, 44(1), 1-23.

Kim, S. (2016). The future of elearning in medical education: current trend and future opportunity. Journal of educational evaluation for health professions, 3. Retrieved from https://www.ncbi.nlm.nih.gov/pmc/articles/PMC2631188/

Kleinert, R., Heiermann, N., Plum, P. S., Wahba, R., Chang, D. H., Maus, M., ... \& Stippel, D. L. (2015). Web-Based Immersive Virtual Patient Simulators: Positive Effect on Clinical Reasoning in Medical Education. Journal of medical Internet research, 17(11), e263. doi: 10.2196/jmir.5035

Lehmann, R., Thiessen, C., Frick, B., Bosse, H. M., Nikendei, C., Hoffmann, G. F., ... \& Huwendiek, S. (2015). Improving pediatric basic life support performance through blended learning with web-based virtual patients: randomized controlled trial. Journal of medical Internet research, 17(7), e162. doi: $10.2196 /$ jmir.4141

Li, T. Y., Gao, X., Wong, K., Tse, C. S. K., \& Chan, Y. Y. (2015). Learning Clinical Procedures Through Internet Digital Objects: Experience of Undergraduate Students Across Clinical Faculties. JMIR Medical Education, 1(1), e1.

Liaw, S. Y., Wong, L. F., Lim, E. Y. P., Ang, S. B. L., Mujumdar, S., Ho, J. T. Y., ... \& Ang, E. N. K. (2016). Effectiveness of a Web-Based Simulation in Improving Nurses' Workplace Practice With Deteriorating Ward Patients: A Pre-and Postintervention Study. Journal of medical Internet research, 18(2),e37. doi: 10.2196/jmir.5294

Margueratt, D. (2007). Improving learner motivation through enhanced instructional design (Doctoral dissertation, Athabasca University). Retrieved from https://dt.athabascau.ca/jspui/handle/10791/126

Montaser, L., Mortada, M., \& Fawzy, S. (2012). Impact of technology on the future of education. Edulearn12 Proceedings, 3881-3887.

Mufeti, T. K. (2005). The Impacts of a New Learning Culture at the University of Namibia. In Proceedings of the 4th European Conference on eLearning (ECEL 2005) (pp. 301-308). UK: Academic Conferences Limited.

Pantziaras, I., Fors, U., \& Ekblad, S. (2015). Training with virtual patients in transcultural psychiatry: do the learners actually learn?. Journal of medical Internet research, 17(2).e46. doi: 10.2196/jmir.3497

Pennaforte, T., Moussa, A., Loye, N., Charlin, B., \& Audétat, M. C. (2016). Exploring a New Simulation Approach to Improve Clinical Reasoning Teaching and Assessment: Randomized Trial Protocol. JMIR research protocols, 5(1),e26. doi: 10.2196/resprot.4938

Rajkomar, A., \& Dhaliwal, G. (2016). Improving diagnostic reasoning to improve patient safety. The Permanente Journal. 15(3), 68-73. 
Rigby, K. T. (2015). Real-time Computer-based Simulation as an Intervention in Aerodynamics Education. Journal of Aviation/Aerospace Education \& Research, 24(2), 1-20.

Rovai, A. P., Ponton, M. K., Wighting, M. J., \& Baker, J. D. (2007). A comparative analysis of student motivation in traditional classroom and elearning courses. International Journal on ELearning, 6(3), 413-432.

Segerman, J. (2013). Residents' Perceptions of Classroom Situated eLearning for Medical Education (Doctoral dissertation). Available from ProQuest Dissertations and thesis database. (UMI No. 789)

Shortliffe, E. H., \& Cimino, J. J. (2013). Biomedical informatics: computer applications in health care and biomedicine. New York, NY: Springer Science \& Business Media.

Smith, N. A., Ashcroft, E., \& Rhodes, K. (2011). Effect of simulation training on the practice of medical students (Doctoral dissertation, University of Wollongong). Retrieved from http://ro.uow.edu.au/cgi/viewcontent.cgi?article=1072\&context=medpapers

Wai, C. C., \& Seng, E. L. K. (2015). Measuring the effectiveness of blended learning environment: A case study in Malaysia. Education and Information Technologies, 20(3), 429-443. 